\title{
Motivational interviewing in general dental practice: A review of the evidence
}

kay, elizabeth

http://hdl.handle.net/10026.1/9427

10.1038/sj.bdj.2016.952

BDJ

Springer Science and Business Media LLC

All content in PEARL is protected by copyright law. Author manuscripts are made available in accordance with publisher policies. Please cite only the published version using the details provided on the item record or document. In the absence of an open licence (e.g. Creative Commons), permissions for further reuse of content should be sought from the publisher or author. 
Final author's draft of a paper published in British Dental Journal 2017 BDJ 221(12):785-791, Dec 2016 doi:10.1038/sj.bdj.2016.952

Motivational Interviewing in general dental practice. A review of the evidence.

Kay, Elizabeth Jane ${ }^{a}$

Vascott, Donna

Hocking, Allice ${ }^{b}$

Nield, Helen ${ }^{c}$

a Peninsula Dental School, Plymouth University, Peninsula Schools of Medicine and Dentistry

b SERIO, Science Park, Plymouth University

${ }^{c}$ British Dental Association, 64 Wimpole Street, London

Key words: oral health promotion, motivational interviewing, systematic review 
Final author's draft of a paper published in British Dental Journal 2017 BDJ 221(12):785-791, Dec 2016 doi:10.1038/sj.bdj.2016.952

\section{Abstract \\ Objectives}

The objective of this study was to systematically review the evidence regarding the use of motivational interviewing in the context of general dental practice, in order that practitioners can decide whether it might be an important skill to develop within their practices.

\section{Data sources}

The results reported in study form part of a larger systematic review which sought to identify whether oral health promotion within dental practice is effective and how its effects can be optimised. Here, we focus on the papers describing motivational interviewing in dental practice published since 1994. The systematic review included searches of 20 online resources (including Ovid Medline and Embase)

\section{Data selection}

Papers which were not about oral health promotion and did not apply the behavioural and psychological theories which underpin Motivational Interviewing, were excluded.

\section{Data synthesis}

This review included eight papers all of which were considered of robust quality in terms of their research methods and seven of which were considered to offer externally valid findings. Five described randomised controlled trials and all of these RCT's demonstrated that interventions including MI had a positive effect on oral health and health behaviour.

\section{Conclusions}

This review shows that motivational interviewing technique which is based on the concept of autonomy support has potential for helping patients with poor oral health. Training in Motivational Interviewing for dental personnel could be a very useful addition to the skill set of practitioners and dental teams. 
Final author's draft of a paper published in British Dental Journal 2017 BDJ 221(12):785-791, Dec 2016 doi:10.1038/sj.bdj.2016.952

\section{Introduction}

Motivational interviewing is a method of working with patients which activates their own motivation and resources, thereby enabling them to change their behaviours. It has previously been shown in systematic reviews to be effective for improving health related behaviours ${ }^{1,2,3}$ Motivational interviewing recognises that behaviour change requires a partnership between patient and clinician in which they develop a collaboration of their individual expertise. That is, Motivational Interviewing relies on a complete acceptance that people (patients) are the experts on themselves and it recognises that people make their own decisions about what they will and will not do, despite the wishes, intentions and knowledge of their clinician.

A motivational interviewer seeks to create a positive interpersonal atmosphere, which is conducive to change but does not expect or demand it. Adopting a motivational interview approach does however offer a challenge to dental practitioners as it requires the dental professional to stop thinking that they have the solutions to patients problems or even 'should' have those solutions.

Much research has suggested that if people are made to feel unacceptable or somehow 'not right' they are less able to undertake changes in their lives. Indeed, 'blaming' the victim of an unhealthy lifestyle has long been considered a very poor starting point for promoting healthful change. Miller and Rolninck ${ }^{4}$ suggest that the more an individual recognises that others accept them as they are, the freer they are to make changes in their lives. Thus, motivational interviewing requires a practitioner to be able to understand other people's frame of reference i.e. to have real empathy. The opposite of empathy is "the imposition of one's own perspective, perhaps with the assumption that the other's views are irrelevant or misguided" 5 , which is perhaps all too often the attitude of a practitioner when faced with a patient with poor oral hygiene. Motivational interviewing instead relies on autonomy support i.e. a complete acknowledgement and belief that another person's choices are entirely their own. This helps to reduce patients' defensiveness and therefore facilitates change. The practitioner rather has to accept that she cannot and indeed should not 'make' people change - and recognising that this paradoxically improves the chances that the clinician will help the patient to behave in a more healthy way.

A final part of the motivational interviewing approach is seeking and acknowledging another person's strengths and efforts. Most of dentistry is about the opposite i.e. finding things 'wrong' with people (diagnosing/assessing patients) and arranging for the 'wrong' things to be fixed. So oral health promotion from an MI perspective is basically about developing a "patients' eye view" and making sure they know that they are not being judged and found wanting. It is about understanding a patients perspective and then supporting them to make the choices that they prefer. So to sum up, motivational interviewing is a person centred ${ }^{6}$ style of conversation which addresses the fact that patients find it very difficult to change, and are resistant to doing so. 
Final author's draft of a paper published in British Dental Journal 2017 BDJ 221(12):785-791, Dec 2016 doi:10.1038/sj.bdj.2016.952

It is a technique that was first described in the literature in 1983 and more than 20,000 articles and 200 randomised controlled trials of MI have been published since. A few of these have related to oral health. The objective of this paper is to review the evidence regarding the use of motivational interviewing to promote positive oral health behaviours in a one-to-one setting, in order that oral health practitioners can decide whether it might offer them a useful skill to add to their armamentarium.

\section{Materials and Methods}

\section{Search strategy}

This review expands on the findings of an earlier review which sought to identify whether oral health promotion within dental practice is effective and how its effects can be optimised ${ }^{7}$; it considered studies of the use of motivational interviewing in the context of general dental practice, studies which investigated methods of promoting oral health in terms of awareness, in terms of health related behaviours, and in terms of health outcomes. Oral health awareness encompasses knowledge of lifestyle impact and diet, as well as oral hygiene practices. The literature search included studies focussing on any of these aspects of oral health.

Search strategies were devised to search the following database catalogues of literature: AMED; CINAHL; Cochrane Library; EMBASE; Medline; PsycINFO; PsycARTICLES; ScienceDirect; SocINDEX; ASSIA; Social Policy and Practice; and HMIC (Health Management Information Consortium). In addition, the following grey literature databases were searched: The Knowledge Network; Intute; MedNar; Copac; EPPI-Centre; EThOS; OpenGrey; and TRIP. Table 1 shows the search strategy employed for Ovid MEDLINE; this strategy was subsequently adapted for each of the twenty databases searched.

In addition to these searches, a call for evidence was issued in October 2014 which revealed four potentially relevant articles which had not been previously identified; one of which was included in the final review. The team also hand searched the references of three relevant systematic reviews, revealing one study which was found to be in scope, but had not been detected by the original searches.

\section{Study inclusion and exclusion criteria}

Studies conducted and published in English from 1994 onwards were included in the review. This date was chosen as the last major review of oral health promotion was published by Kay and Locker in $1997^{\circ}$ and which included papers published up until 1994. The search was not limited by country because the need for oral health promotion is universal.

Articles were excluded if they reported on: the evidence base underpinning oral health advice for patients; clinical dental treatments; approaches to tackling clinical diagnoses of dental anxiety and phobia; oral health needs assessments; community-based oral health promotion programmes and interventions; oral health promotion and dental treatment in residential or care settings (including hospitals and nursing and residential care homes for children, young people and adults); any other methodology other than primary research. Having removed the 
Final author's draft of a paper published in British Dental Journal 2017 BDJ 221(12):785-791, Dec 2016 doi:10.1038/sj.bdj.2016.952

excluded papers, the papers were then grouped according to whether they addressed one of the following research questions.

- Does the application of behavioural and psychological theory to oral health behaviour lead to effective oral health promotion interventions?

- What is the most effective mode of delivery (channel) for oral health promotion?

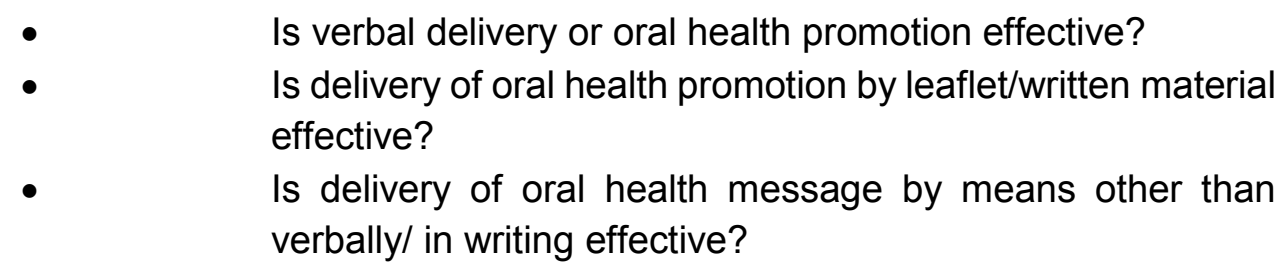

- What is the content of oral health messages and how does content influence effectiveness?

- What is the influence of 'receiver' characteristics on the effectiveness of oral health promotion?

- What influence do 'sender' characteristics have on the effectiveness of oral health promotion?

- What influence does framing have on the effectiveness of oral health promotion messages?

- What are the barriers and facilitators to effective oral health promotion?

- What factors affect patient and facilitators to effective oral health promotion?

- What factors affect patient satisfaction and motivation after a dental visit?

- $\quad$ Are oral health promotion messages more likely to have an effect on patients if they are linked to wider health outcomes?

This paper reports on the evidence which addressed the first of these research questions.

\section{Data extraction}

Once duplicates had been removed, titles and abstracts were screened for obviously irrelevant studies, which were excluded. Titles and abstracts were then reviewed by the team's content experts who removed studies which did not specifically fit the inclusion and exclusion criteria. Where there was insufficient data in the title or abstract, or both, to make a clear decision regarding eligibility of studies, the full text of the paper was obtained. Details of excluded studies at both stages were documented. All papers were then independently assessed for appropriateness to the review's aims by two reviewers. Where there were discrepancies in the final decision of whether the article was to be included or excluded, a third reviewer was consulted in order to reach a consensus. All details of inclusion and exclusion at this stage were documented in an audit trail. 
Final author's draft of a paper published in British Dental Journal 2017 BDJ 221(12):785-791, Dec 2016 doi:10.1038/sj.bdj.2016.952

Figure 1 illustrates the flow of studies through the sifting process. References were managed using EndNote; where databases were not compatible with Endnote, search results were recorded in Microsoft Excel.

\section{Quality Assessment}

The internal and external validity of the included studies (both quantitative and qualitative) were assessed by the quality appraisal checklists provided in Methods for the development of NICE public health guidance (third edition). Each study was rated $(++,+$ or -$)$ to denote its quality. A study awarded (++) indicated that the study had been designed in such a way to minimise bias; studies awarded (+) indicated that the study may not have addressed all potential sources of bias; and studies awarded (-) indicated that there were aspects of the study where significant sources of bias may exist. Quality assessments for each of the included papers were conducted individually by the researchers, but in the same room to allow for discussion about any difficult or contentious judgements, so that consensus was always reached. An additional reviewer independently repeated $10 \%$ of the quality assessments to ensure consistency. Following this, where there were reporting issues or where the amount of information provided made it difficult to make judgments, the quality assessments were reconsidered again by two reviewers until agreement was reached. The evidence provided by each study, the quality assessment and the outcomes from each study were recorded in evidence tables.

\section{Strength of the evidence}

Evidence was considered strong if more than one study rated (++) or more than one Randomised Controlled Trial (RCT) rated $(+)$ reported an effect. Evidence for a finding was considered moderate if supported by one or more non RCT studies rated $(+)$, and was considered weak if the evidence was supported only by studies considered to be of low quality $(-)$.

\section{Results}

The search revealed 52 papers which reported on oral health enhancing activities, which were, or could be, carried out within general dental practice. Articles describing community based, or school based oral health promotion were not included. Finally, papers which did not focus on motivational interviewing were discarded leaving 8 papers which were reviewed in detail.

The first three included papers $9,10,11$ were reports which described aspects of the same randomised controlled trial. They described an individually tailored oral health educational programme, based on a cognitive motivational interviewing approach, involving 113 adult patients (60 females and 53 males) with chronic periodontitis, who were randomly allocated to an experimental or a control group. The intervention group received an individually tailored oral health educational programme based on cognitive behavioural principles. The individual tailoring for each participant was based on participants' thoughts, intermediate, and long-term goals, and oral health status. The control group $(n=56)$ received standard periodontal care with demonstrations of oral hygiene and structured information. The effect of the programme 
Final author's draft of a paper published in British Dental Journal 2017 BDJ 221(12):785-791, Dec 2016 doi:10.1038/sj.bdj.2016.952

on gingivitis [gingival index (GI)], oral hygiene [plaque indices (PLI) and self-report], and participants' global rating of treatment was evaluated three and 12 months after oral health education and non-surgical treatment. Between baseline and the 12-month follow-up, both $\mathrm{GI}$ and PLI improved more in the experimental group than in the control group. The mean gainscore difference was 0.27 for global GI [99.2\% confidence interval $(\mathrm{Cl}): 0.16-0.39$, $\mathrm{p}<0.001$ ] and 0.40 for proximal $\mathrm{Gl}(99.2 \% \mathrm{Cl}: 0.27-0.53, \mathrm{p}<0.001)$. The mean gain-score difference was 0.16 for global PLI (99.2\% Cl: $0.03-0.30, p=0.001)$, and 0.26 for proximal PLI $(99.2 \% \mathrm{Cl}$ : 0.10 $0.43, p<0.001)$. The participants in the intervention group reported a higher frequency of daily inter-dental cleaning and were more certain that they could maintain the attained level of behaviour change. The individually tailored oral health educational programme was efficacious in improving adherence to oral hygiene for a year. The largest difference was for interproximal surfaces. This paper indicated that patients in the motivational interviewing based intervention were regarded as achieving treatment success, or had higher odds of treatment success.

Another randomised controlled trial ${ }^{12}$ by Munster Halvari tested the hypotheses that a dental intervention designed to promote dental care competence in an autonomy-supportive way, would positively predict patient motivation, increase dental home care, enhance perceived dental competence, and improve dental health related behaviours. It was also hypothesised that the intervention would decrease both dental plaque and gingivitis over 5.5 months. A randomised two-group experiment was conducted at a dental clinic with 141 patients ( $\mathrm{M}$ age $=23.31$ years, $S D=3.5$ ), with pre- and post-measures (after 5.5 months) of motivation, dental behaviour, dental plaque, and gingivitis. The intervention made a moderate difference to dental behaviour, but autonomous motivation and perceived competence, perceived autonomy, dental plaque, and gingivitis all improved considerably. Considering the very large effects on reductions in dental plaque and gingivitis, promoting dental care competence in an autonomy-supportive way, seemed to have important practical implications for dental treatment, home care, and oral health.

A study by Kakudate et al. ${ }^{13}(+)$ sought to determine whether the application of a structured programme based closely on the principles of motivational interviewing, which developed patients self-efficacy via the transtheroretical model of behaviour change was more effective than traditional oral hygiene instruction. Thirty-eight adult patients with chronic periodontitis were randomly assigned to two groups. The intervention group received $\mathrm{Ml}$ counselling for ten minutes after traditional oral hygiene instruction. In both groups, oral hygiene instruction was given once a week, and performed three times in total for three weeks. The control group was given traditional oral hygiene instruction for 20 minutes. Clinical characteristics, deposition of dental plaque, frequency and duration of brushing, frequency of interdental cleaning and scores based on a scale of "self-efficacy for brushing of the teeth" were compared in both groups. There were no differences between the two groups in clinical, demographic, behavioural and self-efficacy characteristics at the baseline examination. However after the third visit, the intervention group had significantly higher self-efficacy, lower plaque index scores, longer brushing duration and higher frequency of inter-dental cleaning than those of the control group. Multiple regression analysis showed significant association of tooth brushing duration with self-efficacy for brushing of the teeth $(p<0.001)$. There is therefore 
Final author's draft of a paper published in British Dental Journal 2017 BDJ 221(12):785-791, Dec 2016 doi:10.1038/sj.bdj.2016.952

evidence that the motivational interviewing approach is more effective for enhancing selfefficacy and behavioural change in oral hygiene than traditional oral hygiene instruction.

Another randomised controlled trial ${ }^{14}$, this time with a cluster design, tested an evidencebased intervention which focussed on the principles of self-efficacy and implementation intention theory, which both underpin the principles of motivational interviewing. The study included 87 dental practices and 778 patients (Patient RCT $=37$ dentists/300 patients; Cluster $\mathrm{RCT}=50$ dentists/478 patients). Controlling for baseline differences, pooled results showed that patients who experienced the intervention had better behavioural (timing, duration, method), cognitive (confidence, planning), and clinical (plaque, gingival bleeding) outcomes. However, clinical outcomes were statistically significantly better only in the Cluster RCT, suggesting that the trial design may affect the results from such studies.

Fjellstrom et al ${ }^{15}$ compared an intervention based on cognitive behavioural theory, which focussed on patient recognition of their own attitudes and behaviours, with traditional oral hygiene instruction, in order to determine the impact of the cognitive behavioural approach in increasing adherence to oral hygiene. Patients in the study were encouraged to keep a diary to document their thoughts and feelings prior to, and during, tooth cleaning. Four participants were divided into two groups; the intervention and the control group. At the first visit, all participants answered a self-reporting questionnaire. The clinical examination consisted of measuring the $\mathrm{PI}, \mathrm{GI}$ and $\mathrm{GBI}$. The same information and instructions were given to both groups and all received toothbrushes, dental floss and professional tooth cleaning. However, the intervention group were instructed to document their feelings and thoughts in a diary. After three weeks, the participants answered the same questionnaire, and the same clinical measurements were conducted at the re-examination. The intervention group brought their diaries for evaluation. At the end of the study, there was a difference in $\mathrm{PI}, \mathrm{GI}$ and $\mathrm{GBI}$ between the groups. The levels of $\mathrm{PI}, \mathrm{GI}$ and $\mathrm{GBI}$ had decreased more in the intervention group than in the control group (no p-values or statistics were given in the paper). The questionnaire also showed that the CBT group had increased their knowledge and awareness about oral health. This pilot study showed that using a modified model of CBT, by keeping a diary, resulted in increased adherence to oral hygiene and knowledge about gingivitis, compared with traditional instruction.

The effectiveness of oral health counselling concerning changes of oral hygiene habits in 11to 13-year-old schoolchildren within a theoretical framework of the motivational interview was tested in a qualitative study ${ }^{16}$. Thirty-one $(n=31)$ schoolchildren were included in counselling sessions that were conducted by four dental hygienists. The audiotaped and transcribed data were analysed qualitatively by using content analysis. At baseline, nearly every schoolchild needed to establish changes in oral hygiene habits but the schoolchildren's readiness for change was often unclear. Giving normative advice was the most commonly used counselling strategy when addressing the need for change, but dental hygienist-led discussions about change and goal setting were related to schoolchildren's changing their oral hygiene habits over the period of a year. The results suggested that the transtheoretical framework might be useful in constructing oral hygiene counselling for schoolchildren and such an intervention should focus on the personal dynamics of change. 
Final author's draft of a paper published in British Dental Journal 2017 BDJ 221(12):785-791, Dec 2016 doi:10.1038/sj.bdj.2016.952

Another study ${ }^{17}$ compared the effect of motivational interviewing with that of traditional health education, on parents of young children at high risk of developing dental caries. The authors enrolled parents of 240 infants aged six to 18 months in the study and randomly assigned them to either a motivational interviewing intervention group or a traditional health education (control) group. Parents in the control group received a pamphlet and watched a video. Parents in the intervention group also received the pamphlet and watched the video; in addition, they received a personalized counselling session and six follow-up telephone calls. After one year, children in the intervention group had 0.71 new carious lesions $(S D=2.8)$, while those in the control group had $1.91(S D=4.8)$ new carious lesions ( $t$ [238] $=2.37$, onetailed $\mathrm{P}<0.01$ ). It was concluded that the intervention was an approach which helped parents to accept dental recommendations about preventing caries in their children, and this had a measurable effect on the children's caries rates and oral health.

\section{Discussion}

This review focused on oral health promotion activities that could be delivered in the context of general dental practice, which aimed to change individual's knowledge attitudes or behaviours in order to influence their oral health. It did not include legislative, regulatory, fiscal, or organisational activities which influence health/oral health. This approach was taken in order to ensure that the conclusions drawn could be applied by dental professionals in dental practices in the UK. This is a much narrower context than that of the review published in 1998 by Kay and Locker. The current review worked from the principle that the evidence base underpinning effective oral health promotion is well established and accepted (Delivering Better Oral Health) and therefore the strategy was to determine 'how' oral health promotion in the dental surgery should be carried out in order to optimise its effectiveness.

Confidence in the findings of this review stem from the methodology used. A broad search strategy ensured that all relevant literature was potentially included. Assessment of the quality, validity and applicability of the studies, and the data extraction process followed a strict and audited protocol. However, the ability of any review to offer clear and unequivocal conclusions is always limited by the quality and heterogeneity of the primary studies included in the review.

The quality of the studies that were relevant to the subject under review was very variable, and the outcome measures used to assess knowledge, behaviour and attitudes were ad hoc measures and therefore only very rarely allowed direct comparisons between studies, and entirely obviated the possibility of meta-analysing the data. Direct comparison between studies and/or meta-analysis would have only been possible for studies that measured the same clinical outcomes, and then only if the interventions had been the same. This required level of similarity between studies was not reached.

Despite the fact that the context is slightly different, the findings of the review to some extent echo the findings of earlier efforts to synthesise the evidence about oral health promotion (7) As in the previous review, the studies demonstrating reductions in plaque resultant upon oral health promotion were almost ubiquitously short term and therefore evidence that changes in oral hygiene behaviour are sustained in the long term is still sparse. When oral hygiene is improved, gingival health is improved, and there is robust evidence to support this. 
Final author's draft of a paper published in British Dental Journal 2017 BDJ 221(12):785-791, Dec 2016 doi:10.1038/sj.bdj.2016.952

Overall a key theme that emerged was that understanding and accepting the lives of patients and the context of oral health within those lives, along with avoidance of negative judgements of those with poor oral health and hygiene, helps to build the therapeutic alliance that is necessary for successful oral health promotion in the dental surgery. This relationship between patient and oral health professional, this therapeutic alliance, is a key factor in the success of oral health promotion in the dental surgery. Thus, greater emphasis on teaching oral health professionals about health psychology, and how people make choices, would make oral health promotion in the surgery more effective.

\section{Conclusion}

There is evidence to show that Motivational Interviewing may be useful in the dental surgery setting and this application should be researched further. It is a learnable technique which can bring to the practitioners an insight into themselves, a release from a sense of failure when patients do not change, and a means of helping patients who wish to invest in their own oral health and recognise their own responsibility for it. The principles of Ml are simple. It would seem from the evidence reviewed that if practioners understand their patient's lives and see the world through their eyes, rather than superimposing their dental point of view, not only does their oral health, but also their well-being, sense of self-mastery and their satisfaction with the dental care they receive also appear to benefit.

\section{Acknowledgements}

This manuscript was informed by an evidence review and analysis commissioned by the National Institute for Health and Care Excellence to support the development of UK guidelines for the promotion of oral health in general dental practice. The full guidance and supporting documents are available on the NICE website https://www.nice.org.uk. The commissioner of this work had no part in the preparation of the manuscript. 
Final author's draft of a paper published in British Dental Journal 2017 BDJ 221(12):785-791, Dec 2016 doi:10.1038/sj.bdj.2016.952

\section{References}

1. Armstrong, MJ, Mottershead, TA, Ranksley, PE, Sigal, RJ, Campbell, TS, Hemmelgarin, BR. Motivational interviewing to improve weight loss in overweight/obese patient: A systematic review and meta analysis of randomised controlled trials. Obesity Reviews 2011; 12: 709-723

2. Burke, BL, Arkowitz, $\mathrm{H}$, Mechola, M. The efficacy of motivation interviewing: a metaanalysis of controlled clinical trials. J. Cons. And Clin. Psych. 2003; 71: 843-861

3. Dunn, C, Deroo, L, Rivara, FP. The use of brief interventions adapted from motivational interviewing across behavioural domains: A systematic review. Addiction. (2001) 96: $1725-1742$

4. Miller, WR, \& Rollnick S. Ten things that motivational interviewing is not. Behav. And Cog. Psychotherapy 2009: 37; 129-140

5. Rogers, CR. The Interpersonal Relationship: the core of guidance. In CR Rogers and B Stevens (Eds). Person to Person: The problem of being human. (pp $89-103)$. Moab, VT: Real People Press

6. Mills, I, Frost, J, Kay, E, Moles, DR. Person-centred care in industry - the patients perspective. Br. Dent. J. 2015: 218; 407-12

7. Kay, E. Vascott, D. Hocking, A. Nield, H. Dorr,C. Barrett ,H. A review of approaches for dental practice teams for promoting oral health. Comm Dent.Oral Epidemiol. Doi.10.1111/cdoe 12220

8. Kay, E, Locker, D. Effectiveness of Oral Health Promotion: a review. No. 7, Health Promotion Effectiveness Reviews Health Education Authority. 1997

9. Jonsson, B, Ohrm, K, Oscarso, N, Lindberg, P. Evaluating an individually tailored oral health education programme based on cognitive behavioural strategies in non-surgical periodontal treatment. J. Clin. Periodont. 2012; 37: 912-919

10.. Jonsson, B, Ohrm, K, Oscarson, N, Lindberg, P. Cost-effectiveness of an individually tailored oral health educational programme based on cognitive behavioural programme based on cognitive behavioural strategies in non surgical periodontal treatment. J. Clinc. Peroidont. 2012: 39; 659-665

11.. Jonsson, B, Ohrm, K, Oscarson, N, Lindberg, P. The effectiveness of an individually tailored oral health education programme on oral hygiene behaviour in patients with periodontal disease: a blinded randomised controlled clinical trial (one year follow up). J. Clin. Periodont. 2009; 36: 1025-1034

12. Munster Halwarin AE. Self-determined motivational predictors of increases in dental behaviours, decreases in dental plaque, and improvement in oral health. A randomised clinical trial. Health Psychol. 2012: 31; 777-788 
Final author's draft of a paper published in British Dental Journal 2017 BDJ 221(12):785-791, Dec 2016 doi:10.1038/sj.bdj.2016.952

13. Kakudate N, Manabu, M, Makoto, S, Kawanami, M. Systematic cognitive behavioural approach for oral hygiene instruction. A short term study. Patient Ed. \& Counsel. 2009; 74 : 191-196

14. Clarkson JE, Young, L, Ramsay, C, Bonner, BC, Bonetti, D. How to influence patient and hygiene behaviour effectively. Journal Dent. Res. 2009; 88: 933-7

15. Fjellstrom, M, Yakob, M, Soder, B. A modified cognitive behavioural model as a method to improve adherence to dental hygiene instructions - a pilot study. Int. J. Dent. Hyg. 2010; 8: 178-182.

16. Kasili, K, Poskiparta, MT, Hettunen, T, Ptetila, I. Oral health counselling in changing school children's oral hygiene habits: a qualitative study. Comm. Dent. Oral Epidemiol. 2006: $34 ; 419-428$

17. Weinstein, $\mathrm{P}$, Harnson, $\mathrm{R}$, Benton, $\mathrm{T}$. Motivating parents to prevent caries in their young children: one year findings. J. Amer. Dent. Assoc. 2004; 135: 731-8

Table 1. Search Strategy used for OVID Medline (including Medline in Process)

1 Health Education, Dental/

2 ((dental or oral) adj3 (health or hygiene or care) adj3 (educat\$ or promot\$ or program\$ or outreach\$ or instruct\$ or teach\$ or message\$ or advice or counsel\$ or intervention\$ or information or advise $\$$ or campaign $\$$ or initiative $\$$ or strateg\$)).ti.

3 (dental\$ adj3 (promot\$ or program $\$$ or outreach or instruct $\$$ or advice or message $\$$ or counsel\$ or intervention \$ or information or advise\$ or campaign\$ or initiative $\$$ or strateg\$)).ti.

4 Oral Hygiene/ed [Education] 
Final author's draft of a paper published in British Dental Journal 2017 BDJ 221(12):785-791, Dec 2016 doi:10.1038/sj.bdj.2016.952

$5 \quad$ Oral Health/ed [Education]

6 Oral Hygiene/ and (educat\$ or promot\$ or program $\$$ or outreach $\$$ or instruct $\$$ or teach\$ or message \$ or advice or counsel\$ or intervention\$ or information or advise\$ or campaign $\$$ or initiative $\$$ or strateg\$).ti.

7 Oral Health/ and (educat\$ or promot\$ or program $\$$ or outreach $\$$ or instruct $\$$ or teach $\$$ or message $\$$ or advice or counsel\$ or intervention $\$$ or information or advise $\$$ or campaign $\$$ or initiative $\$$ or strateg\$).ti.

8 Public Health Dentistry/ or Community Dentistry/

9 exp Preventive Dentistry/

10 ((dentist $\$$ or dental) and ((public adj3 health) or (community adj3 health) or (community adj3 (program\$ or project\$)))).tw.

11 ((dentist\$ or dental) and (health adj2 (general or public))).ti.

12 ((dentist\$ or dental) adj4 ((early adj intervention\$) or (early adj diagnos\$) or prevent\$)).tw.

13 (dentist\$ or dental).tw. and (exp public assistance/ or medicaid.tw.)

14 exp Periodontal Diseases/pc [Prevention \& Control]

15 exp Tooth Diseases/pc [Prevention \& Control]

16 Oral Hygiene/

17 Oral Health/

18 ((Oral or dental) adj3 (health or hygiene or care)).tw.

19 (toothbrush\$ or floss $\$$ or interdental or dental or dentist\$ or dentition or tooth or teeth or mouthwash\$ or mouthrins\$ or toothpaste\$ or dentifrice\$ or caries or periodont $\$$ or gingiv\$).tw.

20 ((caries or periodont\$) and (prevent\$ or control\$)).ti.

21 exp Health Promotion/

22 Patient Education as Topic/

23 Health Education/

24 Health Communication/

25 Information Dissemination/

26 Persuasive Communication/

27 exp Educational Technology/

28 exp "Tobacco Use Cessation"/mt

29 exp Substance-Related Disorders/ed, pc [Education, Prevention \& Control]

30 exp Diet/ed [Education]

31 ((health or prevention or preventive) adj3 (promot\$ or educat\$ or instruct $\$$ or advice or program $\$$ or outreach or communicat $\$$ or information or message $\$$ or counsel\$ or intervention $\$$ or advise $\$$ or campaign $\$$ or initiative $\$$ or strateg\$)).ti.

32 exp Dental Staff/

33 exp Dentists/

34 dental auxiliaries/ or dental assistants/ or dental hygienists/ or dental staff/

35 ((dental adj (nurse\$ or assistant\$ or (care adj professional\$) or hygienist\$ or therapist\$ or (surgery adj assistant\$) or auxiliar\$ or staff\$ or (health adj educator\$) or (practice adj manager\$) or receptionist\$)) or (oral adj health adj educator\$)).tw.

36 exp dental care/

37 Group Practice, Dental/ or Partnership Practice, Dental/ or General Practice, Dental/ or Practice management, Dental/

38 (Dental adj5 (practice\$ or clinic or clinics or office\$ or facility or facilities)).tw.

39 exp Dental Facilities/ 
Final author's draft of a paper published in British Dental Journal 2017 BDJ 221(12):785-791, Dec 2016 doi:10.1038/sj.bdj.2016.952

40 (Case reports, or clinical trial, all or comparative study or interview or meta analysis or multicenter study or observational study or systematic reviews or review).pt.

41 (randomi\$ or quantitat\$ or qualitat\$ or placebo or randomly or (control adj3 (area or cohort $\$$ or compare $\$$ or condition or design or group $\$$ or intervention $\$$ or participant $\$$ or study))).tw.

42 (Trial or (multicent\$ or multi-cent\$) or pilot or review\$ or follow-up or (follow\$ adj up\$) or outcome $\$$ or study or studies or design or designs or research or ethnograph\$ or intervention\$ or observation\$ or case or evaluat\$ or monitor\$ or program\$ or model\$ or process or interview or interviews or (mixed adj method\$)).tw.

43 exp empirical research/

4440 or 41 or 42 or 43

45 exp Nursing/

46 (midwife\$ or midwives or ((geriatric or (occupational adj health) or orthop*edic or $\mathrm{p}^{*}$ ediatric or psychiatric or (public adj health) or school or oncology or nephrology) adj (nurse or nurses))).tw.

47 ( $\mathrm{p}^{*}$ ediatrician\$ or obstetrician\$ or doctor\$ or oncologist\$ or forens\$ or (intensive adj care) or (critical adj care) or (family adj physician\$) or technician\$ or laborator\$).tw.

4845 or 46 or 47

491 or 2 or 3 or 4 or 5 or 6 or 7

508 or 9 or 10 or 11 or 12 or 13 or 14 or 15 or 16 or 17 or 18 or 19 or 20

5121 or 22 or 23 or 24 or 25 or 26 or 27 or 28 or 29 or 30 or 31

5250 and 51

5349 or 52

5432 or 33 or 34 or 35

5536 or 37 or 38 or 39

5654 or 55

$57 \quad 53$ and 56

$58 \quad 57$ not 48

59 animals/ not humans/

$60 \quad 58$ not 59

61 limit 60 to english language

62 limit 61 to $y r=" 1994$-Current"

$63 \quad 44$ and 62 
Final author's draft of a paper published in British Dental Journal 2017 BDJ 221(12):785-791, Dec 2016 doi:10.1038/sj.bdj.2016.952

Fig 1. Flow of Studies

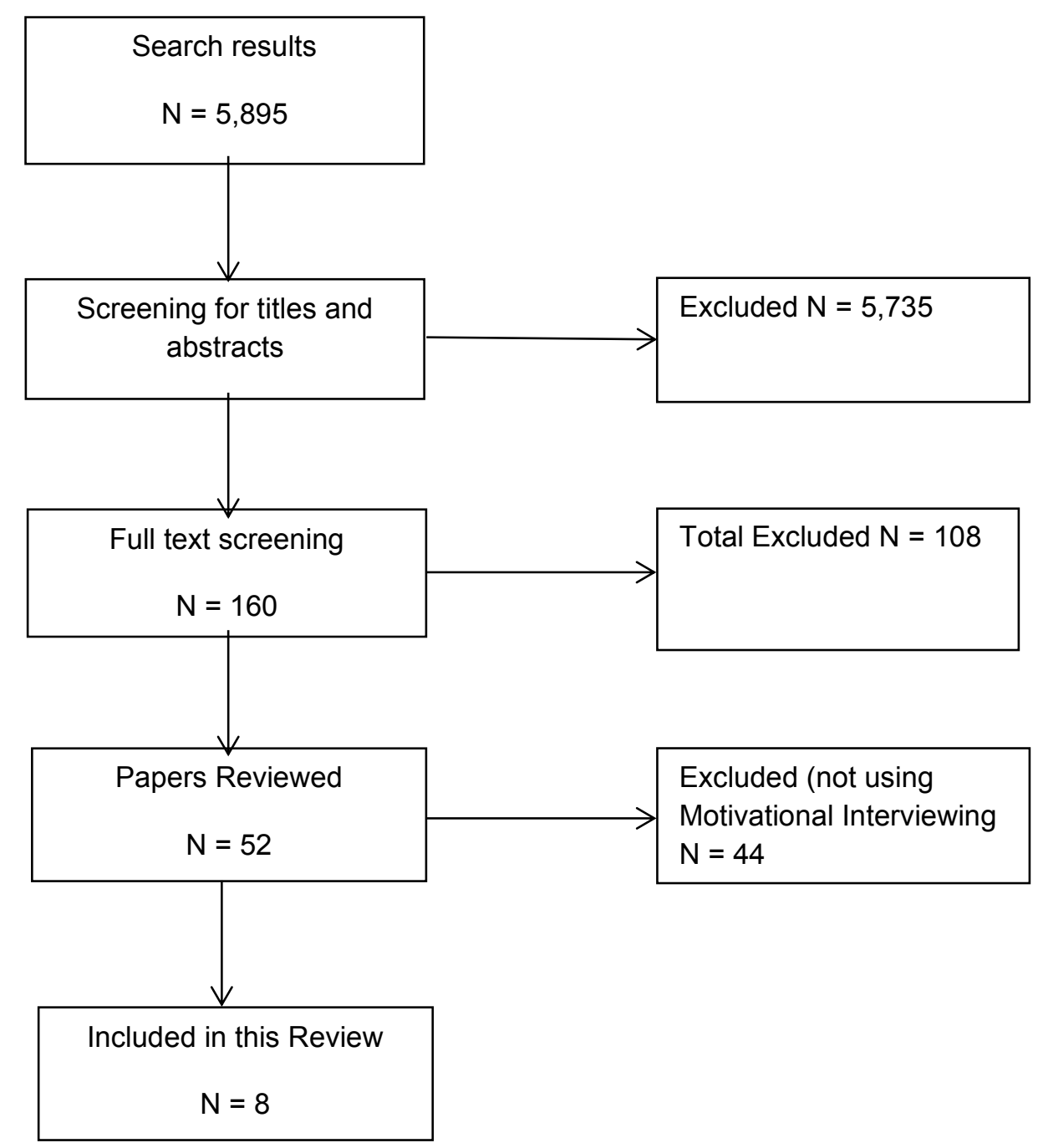


Final author's draft of a paper published in British Dental Journal 2017 BDJ 221(12):785-791, Dec 2016 doi:10.1038/sj.bdj.2016.952

Table 3. Does the application of behavioural and psychological theory to oral health behaviour lead to effective oral health promotion interventions?

\begin{tabular}{|c|c|c|c|c|c|c|c|c|}
\hline Studies & Design & Quality & $\begin{array}{l}\text { External } \\
\text { Validity }\end{array}$ & $\begin{array}{l}\text { Population \& } \\
\text { setting }\end{array}$ & Intervention & Comparison & $\begin{array}{l}\text { Outcome } \\
\text { measures }\end{array}$ & $\begin{array}{l}\text { Positive } \\
\text { finding }\end{array}$ \\
\hline $\begin{array}{l}\text { Jonsson et al. (2009, } \\
\text { 2010, 2012) } \\
\text { (3 papers) } \\
\text { Sweden }\end{array}$ & RCT & ++ & ++ & $\begin{array}{l}\text { Patients with } \\
\text { periodontal } \\
\text { disease. Mean age } \\
52.4 \text {. } \\
\text { Setting = specialist } \\
\text { periodontic clinic } \\
\text { in Sweden }\end{array}$ & $\begin{array}{l}\text { Individual oral health } \\
\text { programme tailored to } \\
\text { each individuals problem, } \\
\text { capacity and goals }\end{array}$ & $\begin{array}{l}\text { Standard care in } \\
\text { form of routine } \\
\text { oral health } \\
\text { preventive } \\
\text { programme }\end{array}$ & $\begin{array}{l}\text { Pocketing } \\
\text { Plaque } \\
\text { Gingival health }\end{array}$ & $\begin{array}{l}\text { No } \\
\text { Yes }\end{array}$ \\
\hline $\begin{array}{l}\text { Jonsson et al. (2009) } \\
\text { Sweden }\end{array}$ & $\begin{array}{l}\text { Quasi- } \\
\text { experimental } \\
(2 \text { cases })\end{array}$ & - & - & $\begin{array}{l}\text { Periodontal } \\
\text { patients aged } 50 \\
\text { and } 60 . \text { Setting = } \\
\text { Department of } \\
\text { Periodontology. } \\
\text { Setting i.e. dental } \\
\text { surgery }\end{array}$ & $\begin{array}{l}\text { Motivational interviewing } \\
\text { at treatment and use of } \\
\text { structured diary. } \\
\text { Psychological } \\
\text { questionnaire. }\end{array}$ & Unclear & $\begin{array}{l}\text { Plaque } \\
\text { Gingivitis } \\
\text { Pocketing } \\
\text { Reported } \\
\text { behaviour }\end{array}$ & $\begin{array}{l}\text { Yes } \\
\text { Yes } \\
\text { Yes } \\
\text { Yes }\end{array}$ \\
\hline $\begin{array}{l}\text { Munster Halvari et al. } \\
\text { (2012) }\end{array}$ & RCT & ++ & + & $\begin{array}{l}\text { University } \\
\text { students }\end{array}$ & $\begin{array}{l}\text { Autonomy - supportive } \\
\text { interview and oral } \\
\text { hygiene instruction } \\
\text { process model }\end{array}$ & Standard care & $\begin{array}{l}\text { Plaque levels } \\
\text { Behaviour }\end{array}$ & $\begin{array}{l}\text { Yes } \\
\text { Yes }\end{array}$ \\
\hline Kakudate et al. (2009) & $\mathrm{RCT}$ & + & + & $\begin{array}{l}\text { Patients with mild } \\
\text { / moderate } \\
\text { periodontal } \\
\text { disease. Setting = } \\
\text { private clinic }\end{array}$ & $\begin{array}{l}\text { Counselling with six-step } \\
\text { method over three dental } \\
\text { visits over } 3 \text { week period }\end{array}$ & $\begin{array}{l}\text { Twenty minutes } \\
\text { oral hygiene } \\
\text { instruction }\end{array}$ & $\begin{array}{l}\text { Plaque Index } \\
\text { Behaviour }\end{array}$ & $\begin{array}{l}\text { Yes } \\
\text { Yes }\end{array}$ \\
\hline $\begin{array}{l}\text { Clarkson et al. (2009) } \\
\text { UK }\end{array}$ & $\begin{array}{l}\text { RCT } \\
\text { (individual } \\
\text { and cluster } \\
\text { analysis) }\end{array}$ & + & + & $\begin{array}{l}\text { Dentate adults } \\
\text { average age } 36.5 \\
\text { who had made an } \\
\text { appointment for a } \\
\text { routine check-up. } \\
\text { Setting = dental } \\
\text { clinic }\end{array}$ & $\begin{array}{l}\text { Oral hygiene education } \\
\text { based on social cognitive } \\
\text { and implementation } \\
\text { theory based on creation } \\
\text { of action plan. }\end{array}$ & $\begin{array}{l}\text { Routine care and } \\
\text { oral hygiene } \\
\text { advice }\end{array}$ & $\begin{array}{l}\text { Plaque score } \\
\text { Bleeding score } \\
\text { Reported } \\
\text { behaviour }\end{array}$ & $\begin{array}{l}\text { Yes (only in } \\
\text { cluster) } \\
\text { Yes (only } \\
\text { in cluster) } \\
\text { Yes }\end{array}$ \\
\hline
\end{tabular}


Final author's draft of a paper published in British Dental Journal 2017 BDJ 221(12):785-791, Dec 2016 doi:10.1038/sj.bdj.2016.952

\begin{tabular}{|c|c|c|c|c|c|c|c|c|}
\hline Little et al. (1997) & $\mathrm{RCT}$ & - & ++ & $\begin{array}{l}\text { Patients aged 50- } \\
70 \text { with mild to } \\
\text { moderate } \\
\text { periodontal } \\
\text { disease. } \\
\text { Setting = dental } \\
\text { clinic }\end{array}$ & $\begin{array}{l}\text { Behaviour change } \\
\text { strategies in groups or } \\
\text { individual }\end{array}$ & $\begin{array}{l}\text { Usual dental } \\
\text { treatment }\end{array}$ & $\begin{array}{l}\text { Plaque scores } \\
\text { Pocket depth } \\
\text { Behaviour }\end{array}$ & $\begin{array}{l}\text { Yes } \\
\text { Yes } \\
\text { Yes }\end{array}$ \\
\hline $\begin{array}{l}\text { Fjellstrom et al. } \\
(2010)\end{array}$ & $\begin{array}{l}\text { Quasi- } \\
\text { experimental }\end{array}$ & ++ & - & $\begin{array}{l}\text { Healthy students. } \\
\text { Setting = clinical }\end{array}$ & $\begin{array}{l}\text { Cognitive Behaviour and } \\
\text { Oral Health promotion } \\
\text { and diary of oral health } \\
\text { behaviours and feelings }\end{array}$ & $\begin{array}{l}\text { Traditional } \\
\text { education and } \\
\text { pictures of } \\
\text { periodontal } \\
\text { disease }\end{array}$ & $\begin{array}{l}\text { Gingival health } \\
\text { Plaque index } \\
\text { Knowledge } \\
\text { Behaviour }\end{array}$ & $\mathrm{NR}^{1}$ \\
\hline $\begin{array}{l}\text { Kasila et al. (2006, } \\
\text { 2008) (2 papers) }\end{array}$ & Qualitative & + & + & $\begin{array}{l}\text { School children } \\
\text { with caries aged } \\
11-13\end{array}$ & $\begin{array}{l}\text { Transtheoretical } \\
\text { behaviour change } \\
\text { counselling. } \\
\text { Autonomy support. }\end{array}$ & Not applicable & $\begin{array}{l}\text { Readiness for } \\
\text { change } \\
\text { Reported } \\
\text { behaviour }\end{array}$ & N/A \\
\hline
\end{tabular}


Final author's draft of a paper published in British Dental Journal 2017 BDJ 221(12):785-791, Dec 2016 doi:10.1038/sj.bdj.2016.952 